Arxiu d'Etnografia de Catalunya, n 1, 1982, 80-106

ISSN: 0212-0372. EISSN: 2014-3885

http://antropologia.urv.cat/revistarxiu

\title{
REFLEXIONES EN TORNO A LA PAREMIOLOGIA
}

Joan J. Pujadas

Departament d'Antropologia de Tarragona Institut Català d'Antropologia. 
Las páginas siguientes corresponden, salvo mínimas correcciones de estilo, al texto elaborado por mí durante el curso 1978-79 dentro del seminario que dirigí en la Facultad de Letras de Tarragona sobre el tema de Paremiologfa. Este seminario ocupó más de la mitad de las sesiones corres pondientes a la recién creada asignatura de Antropologfa Cognitiva.

Aquel curso me $v i$ rodeado de un grupo entusiasta de antiguos alumnos mfos de la Facultad de Filología. La experien cla de trabajo interdisciplinario fue extraordinariamente po sitiva, aunque estuvo totalmente huérfana de apoyo institueional, razón por la cual el proyecto iniciado entonces, los materiales recogidos sobre el terreno en las dos salidas rea lizadas, Junto con muchas ilusiones puestas, quedaron aletar gadas (más bien colapsadas) dentro de ese ambiente de atonía y mediocricidad que pugna por adueñarse del trabafo de los universitarios.

La publicación de estas páginas de reflexión tres años después, cuando han quedado en la cuneta del camino varias ocasiones perdidas para establecer nuevas alternativas al frio y esterilizante laborar de los compartimentos estanco, significa una actitud voluntarista para superar la crisis de esperanza y significa también una apuesta de futuro.

La responsabilidad de esta empresa nos corresponde ente ramente a los universitarios que, con nuestro trabajo y nuestras actitudes, hemos de marcar pautas a las fóvenes ge neraciones. Hay que hacer un esfuerzo colectivo por romper los cfrculos viclosos de ese academicismo trasnochado que practicamos a menudo. La experiencia me ha demostrado en es tos últimos años que, siempre que se han hecho propuestas imaginativas $y$ se ha motivado a nuestros estudiantes, éstos 
han respondido con creces a las espectativas. Esta verdad es tanto más cierta en una pequeña estructura, mucho más cálida y humana, como es el caso de Tarragona.

Quiero dedicar este trabajo a aquellas personas que com parten conmigo esta inquietud de trasponer los lifmites disciplinarios, en busca de nuevos enfoques, y muy especialmen te a Ma Dolors López, Joan Mateu, Joan Pàmies, Montse Font y Conxita González. Asimismo, quiero expresar la deuda contraída con todos nuestros informantes y amigos del pueblo de Vila-Rodona, quienes esperan, pacientes, que algún dfasean publicados todos los materiales que nos proporcionaron en las intensas fornadas de encuesta realizadas en ese magnffico pueblo del Alt. Camp.
Uno de los hechos que nos ha de mover a los etnolíngüis tas a indagar dentro de este rico campo de la paremiología es el hecho de que los trabajos realizados en este dominio es el masta el momento presente han consistido en meras listas o inventarios de paremias. Inventarios realizados con absoluta desconsideración respecto a los contextos lingüístico y situacional, que permitan ubicar los procesos de producción sintagmática en el amplio marco del comportamiento comunica clonal: entendiendo que los procesos de producclón sintagmá tica se configuran apartir de la definición que hace Leach del acto de cultura como acto de comunicación y viceversa. utilizaremos los conceptos paralelos de sintagma lingüfstico (en el sentido estructural-funcional tradicional) e introduciremos un metafórico sintagma cultural, entendido como aquella cadena articulada de comportamientos dentro de un marco cultural definido. De hecho, partiendo de la distinclón hecha por K.L. Pike entre actividad verbal y no ver bal, hay que concluir que sus tagmemas son las unidades mínimas de comportamiento verbal-no verbal en las que se artí cula el sintagma cultural entendido como un todo, incluída la actividad língüfstica sistemática, las realizaciones de tipo onomatopéyico, que a veces florecen en la conversación, asf como los gestos expresivos, el hurgarse la nariz, mirar le el trasero a las chicas, estar en el bar con los amigos, llevar corbata o tener el pelo largo, usar macuto, "fumar", etc. y todo un continuum de rasgos más que constituyen ese cfrculo vicioso que se produce entre el hecho en $s i$ y el contexto global que enmarca ese hecho. Ambos elementos, hecho y contexto, poseen continuidad estructural y están en un permanente Juego dialéctico.

Hemos de revisar todos aquellos postulados que sirvan de base para la elaboraclón de un método y unas técnicas de campo que nos permitan llegar a profundizar en el conoci-

mlento del hecho paremiológico, situándolo en unas coordena das de empirismo émico. Se trata de evitar la 
de postular la existencia del refranero general de una lengua, entendido como un confunto coherente de paremias, correspondientes al ámbito de una sociedad y una cultura y por ello, representativo de éstas de algunas forma. Sabemos que la lengua, sin embargo, entendida como sistema, es un constructo teórico, un confunto de normas y reglas, tal como son descritas por los lingüistas. La lengua no es, pues, una categorfa referente a la realidad lingüfst $\underline{i}$ ca, empíricamente observable, en donde podamos delimitar marcos de referencia comunicativa y/o cultural. Las formas de habla, los discursos etnográficamente enmarcados, si son realidades empíricas y constituyen marcos referenciales en los que observamos el proceso de producción y reproducción paremiológica.

El otro aspecto relevante, que constituye una conditio sine qua non para la interpretación lexicológica de las paremias, consiste en el estudio de los agentes de la produccíón paremiológica, en el de los contextos situacionales que enmarcan dicha producción y, en definitiva, en el estudio de los otros elementos lingülsticos y extra-lingüisticos que sirven de catalizadores para la utilización de los caudales paremiológicos en el discurso comunicativo.

No resulta pertinente, etnográficamente hablando, hablar del corpus paremiológico del castellano o del catalán. Nuestra unidad de análisis se basa en unidades etnográficas concretas en las que distinguimos la utilización de un conjunto más o menos amplio de paremias, que son producidas en una u otra lengua. En todo caso, podríamos hablar de un corpus paremiológico en castellano o en catalán, por ejemplo, lo cual supone atribuir a la palabra corpus un mero valor de agrupación, o reunión, y que no tiene por qué constituír un todo coherente.

Como paremiólogos, tan sólo podemos seguir dos estrategías. Una de ellas es la seguida por tantos insignes folklo ristas y filólogos del pasado, consistente en la mera recolección de paremias, cualquiera que sea su origen; la finalidad era, en definitiva, mostrar la gran riqueza del saber popular. La otra estrategia es la ya apuntada, basada en un criterio cualitativo, en el intento de explicar texto y contexto; es decir, la paremia en tanto que unidad del discurso real de personas, en marcos referenciales que pueden ser estudiados por nosotros, y que nos permiten extraer el significado, la intencionalidad exacta, evaluar la importancia de la paremia en la sintagmática comunicativa de unidades socio-culturales especificas.

La paremiología etnográfica es la únfca alternativa que yo conozco para hacer posible un verdadero análisis léxicosemántico, pues nos aporta la contextualización necesaria para establecer las condiciones de producción y reproduccíon paremiológica. Ya sabemos, por otro lado, que son esté riles los esfuerzos por incidir en el análisis del significado de las paremias por referencla a los contextos origina ríos de cada paremia. Establecer los orf́genes de la paremia es una utopfa inalcanzable, además de ser un falso problema dentro del estudio del universo paremiológico. La paremia, como tantas otras manifestaciones de la llamada "cultura po pular" se pierde en el anonimato del ingenioso local, del campesino racionalista que, en su intento de transmitir su conocimiento sobre su mundo, buscaba fórmulas mnemotécnicas que suplieran su analfabetismo. El trabajo de campo nos ha mostrado con harta saciedad que las mismas paremias no tan solo son conocidas y utilizadas por doquier, sino que por doquier son reivindicadas como fruto del ingenio del propio pueblo. Las mismas paremias las vemos traducidas a diferentes lenguas, pues al fin y al cabo los campesinos, los pastores, o los artesanos castellanos, o catalanes, o gallegos, no son tan diferentes y sus experiencias del entorno son muy similares. As 1 tenemos como a estas paremias recogidas en la primavera de 1979 en el pueblo catalán de Vila-Rodona: 
/La pluja al gener omple el graner/

/El Juny la falç al puny/

/Si plou a l'abril, cada gota val per mil/

le corresponden equivalentes idénticos en castellano, como los recogidos en la antología de Martínez Kleiser:

/Lluvias en enero, llenan cuba, tinaja y granero/ /Lluvias pocas en enero enriquecen el granero/ /Junio hoz en puño, de verde y no de maduro/ Junio y jullio, hoz en puño/

/Aguas en abril, vengan mil/

/En abril, cada gota vale por mil/.

\section{EL AMBITO de LO PAREMIOLOGICO Y LA CULtURA POPULAR.}

"Gente refranera, gente embustera"

"Hombre refranero, hombre de poco dinero"

"Afanes y refranes, herencla de segadores y gañanes"

Para Martínez Kleiser, autor de la más monumental recopilación paremiológica de todos los tiempos y latitudes, la existencia de tan despectivos conceptos respecto a los refranes "nacen del escaso crédito concedido al pueblo, su au tor. En los talleres del pueblo fueron elaborados los refra nes; encierran un cuerpo de doctrina que no fue proclamado en las aulas de ningún centro universitario; pretenden alec cionarnos sin título ni birrete; brotaron frente a las brasas de un hogar pueblerino, sobre los surcos de un arado, bajo el tejadillo ruinoso de un atrio parroquial; huelen a romero y tomillo, cuando no a los ajos y cebollas del plebe yo condumio; les falta empaque y distinción; son hijos expó sitos sin padres conocidos; no pueden tener entrada en los saraos del idioma; llenen en buena hora las alforjas de San cho, pero no pretendan cobijarse bajo el yelmo de Don Quifo-
Dicho en otros términos, el refranero ha quedado reiega do "allende las fronteras del lenguaje culto". Y ello comporta que la lingǘstica y su hermana mayor la filología, caracterizadas por su filiación aristocrática, casi nunca han prestado atención a tan vulgar forma de expresión de la sintesis verbal del pensamiento de la "chusma" y del "vulgo". En verdad, es que la lingüística hasta años muy recientes no ha considerado seriamente el estudio de tal forma de modalidades como objeto legitimo de preocupación, y aún hoy los trabajos y las consideraciones sobre el tema, por parte de lingüistas y filólogos es muy marginal. Una expresión vi va de la repugnancia y del reparo "normativos" hacia las formas de expresión popular (verbales y no verbales) las te nemos en dos aflrmaciones muy recientes realizadas por dos especialistas indiscutibles en Paremiología castellana:

"Reconozcamios que, cuanto nos dicen los refranes, solemos ofrlo son rientemente, como si supleramos que su menuda reflexión, empujadors a la derecha a a la izquierda, se nos brinda desde una ladera nisterlosa y benévola, con la mfnima coacción que supone el hacetnos saber los buenos resultados que dio a otros el atemperarse a -

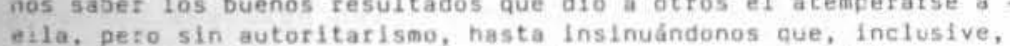
1a salud puede estar en desobedecerlos, para lo que, pintorescanente, suele encantrarse en el mismo corpus una indicactón contraHa. in a quien madruga oios le ayuda" versus "No por mucho madrugaz aranece más temprano"). En 1978, si hemos de ser sinceros, cuanco surge un refrán en las conversaciones habituales, éstas se detlenen un instante, acusando clerta divertida sorpresa. Sólo en los geclos campesinos, se mueven en su medio natural y los diálogos son boco mas que un peloteo de refranes, sustentadores de tesis opuestas, que acaba ganando el que dispone de un padrino más avezado".

$$
\text { (Calvo-Sotelo, 1978: vi11). }
$$

"(. ...) se desilzan en los refranes 1lcencias de lenguaje que se adentran unas veces, $\sin$ embarazo, por los ranchos de la groseria y traspasan otras, ilbremente, las fronteras de la clerofabla de Is profenación y de la abscenldad. Gran problema para el prudente plecclonador. Su espiritu selectivo se halla colocado ante dos $s$. pura toda clase de mercancias paremiolólcas que pretenden desembarcar en él, y la de talar por la raiz cuantos dichos ofendan al puoor, a la $r_{e} \circ$ al buen gusto. En el primer caso resultaria un 11 Ea el segundo muchos lectores por sus crudezas a enseñanzas noclvas, 
pueblo tras un velo de miramientos y rubores $(\ldots \ldots)$ continúan pues, en el lugar que les corresponde aquellos que, al llegar al acerbo, contenfan supersticlones falsas, creencias vulgares, insinuaciones torpes aunque ingeniosas, irreverencias menos reales que sentidas, y voces malsonantes para ofdos poco avezados a las 11 cenclas del lenguaje popular."

(Martinez Kleiser, 1953: xx).

Ambos textos son expresiones claras de una actitud pater nalista y mitificadora de los valores del acerbo popular, en la que los valores proplos del "campesinado" son reducidos a categorfas residuales del sistema de clasificación de la cul tura dominante. Calvo-Sotelo, que debe buena parte de su fama no a su trivial obra de dramaturgo sino a su programa televisivo dedicado a los refranes ("La bolsa de los refranes" anos 1976-78), caracteriza el fenómeno paremiológico de esta forma:

- "Menuda reflexión" (reconoce a la "cazurrerfa" propia del campesino el don de la reflexión, si bien en pequeñas dosis, pues obviamente la filosofía que subyace al pensamiento campesino no puede tener parangón con las agudezas del lenguaje de los salones de la Corte -que son los que establecen la norma).

- "Mínima coacción benévola" (Hay que suponer, por supuesto, que la norma de conducta, supuesta o sugerida por el refrán, carece de valor pues proviene del anonimato y no está avala da por el prestiglo de un "patricio" del saber y de las letras, cuyas reflexiones tienen poder normativo).

- "Divertida sorpresa" (Frente a las agudezas y al refinado ingenio de los cenáculos y mentideros intelectuales resulta chocante la utillzación del refrán, producto tosco y burdo del pueblo, pues supone falta de imaginación y negación del carácter creativo de la élite (también intelectual, que debe mantenerse a la page $y$ no dejarse influir por recursos arca 1 zantes del lenguafe)l.
- "Los diálogos campesinos son un peloteo de refranes" (¿Esta afirmación debe ser el resultado de dilatadas estancias sobre el terreno o, tal vez, una simple generalización ideali zante y esquematizada de 10 que es la "lengua vulgar o popu lar").

Frente a la labor marginal y superflua de Calvo-Sotelo dentro del campo de la paremiologfa (en el que hay que considerarlo un amateur, a pesar de sus pedantes pretensiones) contrasta la labor titánica de Martínez Kleiser, de la que su Refranero General Ideológico Español es una muestra permanente para las generaciones venideras. Sin embargo, es grave constatar cómo el espiritu que allenta al insigne paremílogo coincide con aquel, y hasta lo supera, en su repug nancia tenuamente contenida hacia la "fuente popular" de la que proviene este rico acerbo cultural y lingúfstico. Veamos, sino, 10 que se desprende de la cita presentada:

"Licenclas de lenguaje (es decir, licencias del lenguaje popular)": (Por el contexto puede deducirse que licencia se utiliza aquí con el valor que posee su derivado Licencioso, acusando al lenguafe popular de tomarse unas libertades indebidas y un mal uso del caudal lingǘlstico. También por el contexto cabe suponer que las 11 amadas "1icencias poéticas" deben ser libertades legitimas reconocidas al genio individual de la creación, mientras que esta legitimidad es negada al autor anónimo del refrán).

"Grosería, clerofobla, profanacíón y obscenidad" (Estos son. los rasgos que caracterizan a una parte, al parecer importante, del caudal paremiológico. Queda claro aquí el trato discriminatorio hacia las paremias, si se compara con la. producción dramática, poética y novelesca que está plagada de "obscenidades", "groserfas" y de "clerofobia" -no de pro fanaciones porque hasta la fecha no se ha logrado la-obraacción-total(?) - y estos rasgos vienen fustificados "por. 
imperativos de guión" (como los desnudos de las macizas ibé ricas). La fuente de esta legitimidad es reflefar la realidad de la vida, del lenguaje cotidiano y de las situaciones encarnadas. Resulta, sin embargo, chocante que a formas "auténticas" de esa realidad cotidiana (los refranes) se les imponga el veto de los valores del "sabio de turno", que se permite la tarea de "flltrar" aquellas para que no ofendan al "pudor" y al "buen gusto", según su especial con cepción y punto de vista (que es el de la clase dominante). Tal vez, si los autores de los refranes fuesen señores con nombre y apellidos y censados en el Registro General de Autores esas "licencias" se legitimarían y se aceptarfa el re frán con valor de sentencia, máxima, aforismo o proverbio. En última instancia, el elemento dominante es el rasgo ideo lógico típico de nuestra sociedad de clases en la que el in telectual tiende a rechazar de forma natural, como espúrea, cualquier manifestacíón "pura" e "incontaminada" del lengua je cotidinao ("vulgar" o "popular"), porque no lleva el mar chamo de autoridad).

- "Espiritu selectivo (......) del prudente coleccionador": (Por encima de cualquier otra consideración sobre la tarea del cientifico, Martínez Kleiser -y con él los "académicos" co mo Calvo-Sotelo-, tienen muy claro que la función primordial es "LIMPIAR, FIJAR Y DAR ESPLENDOR" lo que, en este caso, significa seleccionar; esto es, decidir con un crite rlo de normatividad qué clase de paremias pueden y deben ser recogidas, porque incluso este material -de reconocido valor "vulgar"- debe ser sometido a los parámetros de la normativización. Se trata de alguna forma de aplicar a nivel cientifico los criterlos polfticos del Despotismo Ilustrado: "todo para el pueblo, pero sin el pueblo". Incluso el refrán, reducto de la "cazurrerfa" del campesino ha de someterse a los criterios de la autoridad intelectual, selectiva. $Y$, por ende, frente a la "prudencia" del investiga dor, tenemos la indiscreción del patán pueblerino).
No cabe ninguna duda de que la Lingüistica y la filologla, como ciencias que derivan del "arte del bien decir y del bien escribir" han sufrido una importante convulsión en su proceso de "cientificación", que las lleva necesariamente hacia estudios basados en el descriptivismo, donde las "opiniones", los "prejuicios" y los "a priori" han de ceder terreno frente a la rigurosidad y la asepsia de la disec-

clón de una realidad sin peros: el habla (tal y como se pro duce). La Dialectología y la Geolingüistica, en un principio, y posteriormente, la Sociolingüística, han sido los en foques de la Ciencia Lingüística que más han contribuído a romper el bloque monolifico de una "ciencia elitista", en donde el objeto de conocimiento quedaba flrmemente reducido en los lifmites de un estrato de la sociedad que era conside rado como representativo y arquetípico de la sociedad en su confunto. De la "Gramática" a la "Fonologfa" hay todo un proceso de revolución cientiffica sobre el que conviene ahon dar (aunque éste no es el lugar para ello).

Como resultado de esta marginación del habla popular co mo objeto de conocimiento cientifico es por lo que el refranero ha recibido un tratamiento escaso e Inadecuado. En prí mer lugar cabe señalar que las grandes recogidas y sintesis de los refraneros populares corresponde más a los folkloristas (interesados por la búsqueda de las rafces del saber po pular y de la cultura de los pueblos) que a los fllólogos o linguistas. Prueba bien evidente de ello la tenemos en la bibliografía que adjuntamos, en la que se prueba con harta elocuencia la manlfiesta superioridad numérica de los traba jos paremlológicos de corte folklorista.

Dentro del ámbito de la Paremiología catalana destacan los trabajos de folklorlstas como S. Farnés, A. Capmany, J. Amades y otros, funto a la labor destacada de algunos dialectólogos como A. Griera (Tresor de la llengua) o la magna empresa de Alcover-Moll (Diccionari valencià-català-balear). 
En el ámbito de los estudios sobre el refranero castella no destacan, junto al moderno trabajo de Martínez Kleiser, las aportaciones de Sorapán de Rieros (1616), Correas (1627), Torres Villarroel (1755), García Moreno (1918), Iturriaga (1944), y la interesante aportación sobre Refranero Médico de Casti11o de Lucas (1940-1970).

\section{EN TORNO AL CONCEPTO DE REFRAN Y SUS AFINES.}

Cabe preguntarse si el caudal paremiológico se reduce a entidades de estructura homogénea, desde el punto de vista de la sustancia y la forma. Consultado el Diccionario de la Real Academia (aceptemos de buena gana, siquiera por una vez, las fuentes normativas) comprobamos como existe media docena larga de conceptos emparentados, si no sinónimos. Se trata de adagio, proverbio, refrán, paremia, apotegma, aforísmo, dicho y sentencia, y tal vez, algunas otras, que dejamos para no resultar reiterativos. Comprobemos, al hilode las definiciones, cuál es el parentesco de todas estas. entidades:

- ADAGI0: Sentencia breve, comúnmente recibida y, las más veces, moral.

- AFORISMO: Sentencia breve y doctrinal que se propone como regla en alguna ciencia o arte.

- APOTEGMA: Dicho breve o sentencioso; dicho feliz. Llámese así generalmente al que tiene celebridad por haberlo proferido o escrito algún hombre flustre o por cualquier. otro concepto.

- DICHO: (2) Palabra o conjunto de palabras con que se expresa oralmente un concepto cabal. Aplícasele varios califica tivos, según la cualidad porque se le distingue. Dichoagudo, oportuno, intempestivo, malicioso. (3) Ocurrencía chistosa y oportuna. (5) Expresión insultante o des vergonzada.

- PAREMIA: Refrán, adagio, proverbio, sentencia.

- PROVERBI0: Sentencia, adagio o refrán.
REFRAN: Dicho agudo y sentencioso de uso común.

- SENTENCIA: (2) Dicho grave y sucinto que encierra doctrina o moralidad.

También habría que incluir el concepto de FRASE PROVERBIAL que, también según la Real Academia, consiste en "la que es de uso vulgar y expresa una sentencia a modo de proverbio; v.gr.: /Cada cual puede hacer de su capa un sayo/."

Calvo-Sotelo (1978), en su Prólogo a la reedición de la obra de Martínez Kleiser ve así el problema:

"Hablo del refrán (...) como si fuese la única palabra con que se conociese ese tipo de locuciones, pero en nuestro Diccionario hay otras que, sin ser sinónimas, aunque alguna casi lo sea, se aproximan tanto que merece la pena el intento de definirlas aisladamen te.

¿Cuâl es el género próximo de todas ellas? Yo creo que "dicho". To das son, en efecto, "dichos", separados por pequeños matices. "D1cha", según el Diccionarlo de la Real Academia "es aquel conjunto de palabras con que se expresa oralmente un concepto cabal". Ningu na de las citadas rechaza su parentesco con "dicho". Es el tronco que las abraza, la rafz fertilisima de dande les sube la savia un 1 ficadora. Pero, naturalmente, eso no nos da la licencia para servirnos de ellas como si significasen $10 \mathrm{~m} 1 \mathrm{smo}$. Desde luego, la más próxima a refrán es proverbio, al extremo de que, a veces por no repetir la una, utilizamos la otra. Sin embargo, una minima aunque sutilisima caracteristica, las deshermana. El refrán es un dichoque se Iimita "strictu sensu" a afirmar una realidad evidente, "En Abril aguas mil", no exige ninguna explicación".

E1 PROVERBI0, para Calvo-Sotelo, "completa la simple constatación de un hecho con un consefo, una advertencía, que la redondea. "Quien ama el peligro perece en él". Añade, por tanto, un plus al simple encadenamiento de los hechos en que consiste el refrán".

E1 ADAGI0, por su parte, suele tender a expresar la sen tencia (igual que el proverbio o el refrán) pero de forma más poética (eso no quiere decir que recurra necesariamente al pareado o al aleluya): "El adagio es un refrán de sangre azul, un refrán un punto más elevado y lírico que ellos, y 
la cazurrería y el aldeanismo son notas extrañas y discordantes de su estilo". (Calvo-Sotelo, 1978: VII).

Dicho lo anterior, cabe concluir que refrán, adagio y proverbio son una misma cosa, porque ¿cómo valorar la frontera "objetiva" entre lo poético y 10 no poético?, ¿cómo va lorar la mayor o menor intensidad de intencionalidad dogmática y prescriptiva de un proverbio o de un refrán?. Es, por ello, frecuente ver estos tres términos como sinónimos.

Mientras tanto el APOTEGMA, según la mayoría de los autores, posee el rasgo distintivo de ser atribuido a una per sona importante o de relieve, pero no posee estructuralmente diferencias de substancia o forma respecto a los conceptos precedentes.

La MAXIMA y 1a SENTENCIA se caracterizarfan por su fondo trascendente, "slendo de mayor copete que los anteriores".

Por último, los AFORISMOS, caracterizados por su tono doctrinal, como regla de oro en el comportamiento dentro del ámbito de una ciencia o arte, quedarfan fuera del ámbito de nuestro interés.

Discrepando respecto a la universalidad del DICHO, como nexo de unión de todos los items anteriores, yo propondría el concepto de PAREMIA, por su no utilización en otro ámbito especifico, como el término más general posible, por ser el único concepto precedente capaz de ser reciclado como concepto metalingǘstico e incorporado como categorfa arbitraria y precisa dentro de nuestra terminología cientifica. Además, se da la circunstancla de que su derivada, PAREMI0LogiA, es el término utilizado de forma indiscutible por los diferentes "eruditos" para referirse a este área de interés.

A esta misma conclusión llega S. Farnés (1913:6):
"Les diferèncles que hi ha entre referta, dita, ditxo, refrà, adagi, proverbis, màximes, sentèncles, aforismes, modismes, frases proverbials seria llarch enumerarles. Una paraula sola les abrassa totes: PAREMIA; d'aquil la veu paremiologia per indicar tot això que'n podriem dir art retòrich del poble, veritable cultura naciona1."

El diccionario Alcover-Moll coincide plenamente con las distinciones realizadas por el Diccionario de la Real Acade mía Española, introduciendo un concepto nuevo, que es el de referta, concepto que aproximadamente coincide con el refrany - proverbi. El catálogo completo, por tanto, a nivel concep tual dentro del área paremiológica está compuesto por los siguientes conceptos: adagi, aforisme, dita (ditxo), frases proverbials, màxima, modisme, proverbi, referta, refrany, sentèncía $y$, claro está, parèmia.

Una nueva e innovadora visión del asunto la da el gran maestro de la Lexicograffa hispana, Julio Casares, quien en su Introducción a la Lexicología Moderna centra su discusión en torno a la dícotomía frase proverblal vs. refrán, reduclendo en éstas todas las demás categorfas.

La FRASE PROVERBIAL se refiere siempre a algo que "se difo o se escribló, y su uso en la lengua tiene el carácter de cita, de una recordación, de algo que se trae a cuento ante una situación que en algún modo se asemeja a la que dió origen al dicho. Su valor expresivo no está en las imágenes que pueda contener, cosa que es esencial a las locuclones significantes, sino en el paralelismo que se estable ce entre el momento actual y otro pretérito, evocado con de terminadas palabras." (Casares, 1969: 190).

Ejemplos de frase proverbial los tenemos en: /Tijeretas han de ser/ (aludiendo al cuento de la mujer que 11 amaba a todo tijeretas y su marido, harto, la tiró al río y, cuando se ahogaba, todavfa hacfa el signo de tijeras con las manos). otro ejemplo, citado por Casares, es: /Hasta verte, Jesús mío/ 
(que aludía a la costumbre de apurar el vaso o farro de vino hasta el fondo, en donde solía haber grabada una inscripción I.H.S., esto es, Jesús).

Esto nos muestra que "mientras los hechos, fábulas, cos tumbres, etc., a que aludían las frases proverbiales, perdu raban en la memoria de los hablantes, éstas tenían su máxima eficacia, la cual va disminuyendo de generación en generación, hasta el punto de que muchas de ellas han dejado de ser comprensibles, no ya para el común de las gentes, sino aún para los investigadores más diligentes y eruditos. Y, sin embargo, en el habla cotidiana las vemos aparecer con valor consabido, por virtud del maravilloso crédito inherente a las palabras, que se dan y se toman como los billetes de banco, cuando a veces la entidad emisora que habría de convertir esos papeles en metálico desapareció hace mucho tiempo sin dejar huella." (Casares, 1969: 191).

otros ejemplos famosos de frases proverbiales son, por ejemplo: lotro gallo me cantara/, /si te vi no me acuerdo/, /no está el horno para bollos/, /dífolo Blas, punto redondo/, /de todo hay en la viña del Señor/, /dame pan y dime tonto/, /de menos nos hizo Dios/, /contigo pan y cebolla/, /con su pan se lo coma/, /cualquier tiempo pasado fue mejor/, lya vendrá tío Paco con la rebaja/, /manos blancas no ofenden/, etc.

En todas estas unidades existen otras tantas referencias a contextos específicos de tipo situacional que son la clave para su desciframiento; esto es, se trata de aquellos. contextos y situaciones que han operado como sincretizadores a partir de un material lingüistico tomado del caudal común del habla cotidiana, pero adquiere por referencia a ese contexto específico un papel propio e individualizado que, una vez fijado en el habla, mantiene su significación aún fuera de las circunstancias generadoras del proceso, si guiendo el principio de la arbitrariedad del signo lingüístico (signo locucional complejo, en este caso).

Frente a esto, el refrán presenta una idea completa en forma de sentencia elíptica en el que suelen relacionarse dos ideas, por 10 menos, utilizando un sentido directo o alegórico, pero con un valor general y universalizante.

Como señala Casares (1969: 192) "a consecuencia de la contraposición de conceptos, la forma del refrán usual es bimembre o, por ampliación de dichos conceptos, plurimembre". Un ejemplo de refrán bimembre es: /Al freir será el reir, y al pagar será el llorar/. Un ejemplo de refrán cuatrimembre: IAl comer de las morcillas, rfen las madres y las hijas, y al pagar, todas a 11 orar/.

Casares también llama la atención de la coincidencia formal de la frase proverbial con el refrán unimembre, seña lando que existe el peligro de confusión. Cita como ejemplo de refrán unimembre: /No se pescan truchas a bragas enjutas/, Ino todo el monte es orégano/, / No es oro todo lo que reluce/. Según él, el refrán unlmembre consiste en un silogismo en el que uno de los términos de la comparación se da como implifito. Así, por ejemplo, el desarrollo completo del prí mer ejemplo serf́a: "Es así que para pescar truchas hay que mojarse; es así que cierta persona no quiere mojarse, luego esta persona no pescará".

Como conclusión y sintesis de su exposición magistral, Casares (1969: 194), concluye con esta trascendental distín ción: "El proverbio (o el refrán, como decimos nosotros), en general, como fruto de experiencias acumuladas, tiene su fundamento en el pasado, pero nace de cara al porvenir; es una enseñanza que se da de forma mnemotécnlca, para que se tenga en reserva hasta que lleque la ocasión de aplicarla. La frase proverbial, por el contrario, no tiene el carácter 
de tal por voluntad del que la inventó ni se destina a la posteridad; es ésta la que a fuerza de repetir y aplicar la frase, le da el carácter de proverbial."

\section{CONSIDERACIONES GENERALES SOBRE EL METODO ETNOLINGUISTICO EN LA ENCUES-} IA PAREMIOLOGICA.

"¿y cuál es la causa determinante de nuestra singular riqueza de nuestra cultura popular? A mi entender, el predorinio de la vida. agricola. Espana ha sido un pais en el que el campo ha primado sobre la industria. Esta se ha desenvuelto en los últimos lustros elefantiásicamente para suerte de nuestras "rentas per capita", pero con merma de la productividad de la vida rural y el caldo de cultivo del refranero ha sido slempre la tierra y no la fábrica. 51 se pasa la infrada por sus lomos podrá verse que enorme proporción de sus sentencias corresponde a la metereologfa, al calendario, a las fuerzas naturales, al mundo animal, a todos aquelios elementos en suma, que son tipica levadura de la vida campesina. El otro mundo, el de los sentimientos, el de las pasiones, está visto e interpretado tabín, no con la agudeza de los dláloges de salón. stanterpretado tamblén, no con la agudeza de los díálogos de salón. sino con la cazurra sabiduría aldeana. El campo, sl, es el gran proveedor del refranero $y$ de ahi la inextingulble vitalidad del huestro

(Calvo-Sote10, 1978: v-vi).

Las brillantes precisiones de Don Joaquín nos mueven a reflexionar sobre los aspectos generales del método más ade cuado para la detección y ulterior análisls del fenómeno pa remiológico, entendido como fenomeno global de comunicación $y$, en este caso, como sintesis verbalizada de unas determinadas condiciones de producción. Se trata, pues, del análisis del texto, pero, sobre todo, dentro de un contexto. Se trata, en suma, de intentar un análisis interdisciplinario, de intentar un verdadero análisis, pues hasta la fecha tan solo se han realizado tímidos intentos y, desde luego, desde una perspectiva urbano-céntrica, selectiva y no-émica.

Tal vez, una intuición del genial lexicólogo Julio Casa res aporte mucha luz al asunto y confirme nuestras hipótesis de partida, en lo que respecta al análisis etnolingüístico de este tipo de material.

"(....) No parecerá Infustificado, dice Don Jullo, sostener que el estudio de los proverbios como tales, y no como textos de lenguastudio de los proverbios como tales, y no como textos de lengua, -conviene insistir en esta distinclón- debe dejarse para la paremlologia, clencla que guarda más relación con el folklore y con la psicologia colectiva a étnica que con las disciplinas lingülsticas."

(Casares, 1969: 203)

¿Cómo hay que entender esta afirmación general del distínguido académico? Plenso que, en primer lugar, queda claro que la paremia, como hecho de lengua, da poco juego anaIftico desde el punto de vista sistemático. Por un lado, desde la perspectiva sintáctica, se presenta normalmente co mo una frase independiente y completa, que se intercala en el discurso, bien de forma directa, bien precedida de fórmu las del tipo: /Como dice el refrán...... o bien/Ya 10dice el refrán....... En un caso, el refrán juega el papel de una subordinada sustantiva (/Ya sabes que: no por mu cho madrugar amanece más temprano/, o bien/recuerda que: de noche todos los gatos son pardos/), en otros casos, cuan do se recurre a la clta del refrán utilizando la estructura de estilo directo, tenemos: /como dice el refrán: quien roba a un ladrón tiene clen años de perdón/. La estructura in terna de la paremia suele ser bimembre, esto es, compuesta por dos oraciones simples, aunque hay muchos casos de estructuras unimembres.

En segundo lugar, desde el punto de vista léxico-semántico, el refrán expresa generalmente una idea completa, reducible las más de las veces a un SN, SAdj., o SPrep. De ello, se deduce, que el refrán resulta una unidad que queda fuera del análisis semántico convencional, ocupando una posición liminal respecto a la ciencia lingüística. Esta limi nalidad o marginalidad es la causa fundamental, para mí, que explica el deficlente, o casl inexistente, tratamiento que ha tenido desde este ángulo. ¿Pero, cuál es la alterna- 
tiva que puede ofrecer un planteamiento interdisciplinario $y$, más concretamente, desde el ángulo de la etnolingüística? Vamos a verlo inmediatamente.

El método etnolingǘstico es heredero directo de las tendencias dominantes en la Antropología Cultural de los úl timos treinta años, período en el que se va configurando el corpus axiomático sobre el que se sustenta nuestra particular forma de aproximación a los fenómenos comunicativos. Nuestro punto de vista es eminentemente empírico, a partir de inducciones basadas en la observación directa de unidades sociales concretas, escogidas en función de unos criterios tipológicos previos, que son fruto inevitable de unas deducciones restringidas. El otro eje de nuestro método con siste en la comparación sistemática y en las correlaciones entre los datos extrafdos de las unidades de observación, descritas etnográficamente, con el fin de configurar unidades de análisis más amplias en donde quepa la generalización, que es el objetivo jegítimo de todo análisis cientif $\underline{1}$ co.

Las técnicas comúnmente utllizadas, y merced a las cuales se produce la acumulación de datos, son básicamente cua tro: la documentación sobre todas las fuentes escritas, la observación directa de los fenómenos que se estudian, 1a participación activa en la(s) comunidad(es) estudiada(s) y, por último, la entrevista en profundidad dirigida a un núme ro limitado y concienzudamente seleccionado de informantes. Por lo que respecta a la documentación de repertorios paremiológicos puede asegurarse que las fuentes publicadas supo nen un corpus exhaustivo de temas y variantes de los ricos acerbos, tanto en lengua castellana como catalana, lo que ocurre es que todas estas fuentes están absolutamente huérfanas de análisis que nos permitan ubicar las unidades pare miológicas como hechos de habla, dentro de unas coordenadas espacio-temporales y socio-culturales, que son los ejes mínimos de contextualización necesarios para realizar una interpretación cientifica de este fenómeno.
Las técnicas de observación directa y de participación activa que constituyen la base del trabajo antropológico so bre el terreno, se muestran extraordinariamente parcas en resultados cuando el objetivo es el registro del discursoparemiológico y su contexto. La razón fundamental es que es te tipo de estructura discursiva, al igual que otros tantos elementos de la llamada cultura popular o/y tradicional, es tán hoy en día en una situación de franca recesión y resulta una tarea muy laboriosa, y en ocasiones estéril, atrapar de forma espontánea el uso de paremias dentro de una conver sación cotidiana en cualquier enclave socio-cultural.

Hay que reconocer, pues, el protagonismo de la entrevis ta en profundidad como estrategia básica para la obtención del caudal paremiológico, culturalmente vigente en una unidad socio-cultural delimitada, como es el caso de una comunidad rural. Por otro lado, quiero matizar la importancla que concedo a la elaboración de las entrevistas en base a un muestreo significativo de las diferentes variables que pueden incidir en el mayor o menor uso de las paremias a $n \underline{i}$ vel de habla: edad, sexo, actividad profesional, grado de instrucción escolar, etc. No pueden usarse, en modo alguno, categorías unificadoras y homogenelzantes para describir la vigencia del repertorio paremiológico de una comunidad.

Nuestra experiencia en Vila-Rodona (Alt Camp) nos permí tió distinguir tres niveles operativos para obtener informa ción, no sólo sobre el nivel de uso, sino también sobre el grado de conocimiento y comprensión del refranero. Estos tres niveles pueden ordenarse así:

(1) Preguntas del tipo: "decir paremias relacionadas con el clima, ciclo agrícola, la salud, las mujeres, la gente de los pueblos vecinos, etc."

(2) Preguntas del tipo: "Conoce Ud. este refrán ....?"

(3) Preguntas del tipo: "Qué significa este refrán ..?" 
Ni que decir tiene que los tipos de encuesta basados en preguntas de las serles (2) y (3) han de ser realizadas con sumo cuidado porque corren el peligro de servir de base a todo tipo de mistiflcación, por cuanto el entrevistador pue de estar condicionando al entrevistado en sus respuestas. Hay que evitar un tono inquisitivo y entender los tres nive les de la encuesta como complementarios, de forma que cuando preguntamos el significado de un refrán concreto, que ha yamos podido oir a otro miembro de la comunidad, pongo por caso, 10 que estamos provocando -insinuando- es toda una se rie de asociaciones mentales que nos pueden llevar a operar sobre el primer nivel de encuesta, que es el deseable. El mayor o menor trabajo en lograr este desencadenamiento, este refrescar de la memoria, nos dará la medida exacta del. grado de desuso de los repertorlos paremiológicos.

La encuesta paremlológica sobre el terreno supone una documentación prevía sobre los aspectos culturales y socioeconómicos de la comunidad, de acuerdo con una guía convencional que recofa todos los items etnográficos básicos (cfr. anexo). Hemos de partir de la hipótesis de la conexión exis tente entre los temas en torno a los cuales giran las paremias y los aspectos más relevantes de la vida social: por. efemplo, los cíclos agrícolas, el clima, la enfermedad, la propledad, la familia ...... Hemos de infelar la encuesta. provistos de un buen repertorlo paremiológico, entresacado de las buenas recopilaciones existentes (cfr. bibliografia) para operar en los nfveles (2) y (3) de la encuesta y 11 egar, si es posible, al nivel (1).

El carácter sistemático de la encuesta viene asegurado por una gufa completa de materiales etnográficos, como laque presentamos en el anexo, que intente recoger las dimensiones básicas en las que se articula la realidad cultural, cuyos reflejos pretendemos estudiar a través del uso y desu so del universo paremiológico, pues tan significativo resul ta el primero, como el segundo.
Por último, quiero señalar el carácter de urgencia que supone la realización de este trabajo, puesto que cada vez es mayor el peligro de una desaparición total de estas formas de la llamada cultura popular o/y tradicional. De cara al futuro resultará interesante poseer, funto a las grandes recopilaciones inertes y fosilizadas, algunos ejemplos de cómo vivían o revivían en el habla de unas determinadas comunidades una serie de paremias que se habfan salvado lallá en el lejano fin del siglo $x(x)$ del desuso total, por mor de conservar algún rasgo funcional. Permítasenos ejemplificar con material de primera mano recogido en Vila-Rodona:

(1) Sobre los enfrentamientos entre pueblos vecinos: /Gent d'Alió, gent de poca educació/

/Lluna nova de cara a Vila-Rodona, lluna vella de cara a VilaVella/

(2) Sobre el calendario agrfcola:

/al Juny la falç al puny/

lal fuliol la forca al coll/

(3) Sobre la climatología:

/La pluja, a l'hivern, és bona per tot l'any/ /Cel rogent, plufa o vent/

(4) Sobre enfermedades:

/L'encostipat l'aire el porta i l'aire se l'endú/

(5) Sobre la muerte:

/La picada d'escurçó no hi ha temps d'extremauciól

(6) Sobre crftica social:

/Amb la dona i amb 1'Ajuntament, no estiguis malament/ /Notaris 1 procuradors a 1 'infern de dos en dos/ 
BIBLIOGRAFIA

AMADES, Joan.

1933 Calendari de refranys. Barcelona. Imp. "La Neotipia". 45 pàg. Biblioteca de Tradicions Populars, X.

1935a Refranys $i$ dites. Barcelona. 102 pàg. Biblioteca de Tradicions Populars, serie C., Vol. XXX.

1935b Refranyer barceloní. Barcelona. La Neotipia. 101 pàg. Biblioteca de Tradicions Populars, sèrie C., Vol. XXVI.

1935c Refranys personals. Barcelona. La Neotipia. 102 pàg. Bíbliote ca de Tradicions Populars, Vol. XXIV.

1935d Oracioner i refranyer mèdics. Barcelona. La Neotipia. 101 pàg. 1936 Refranyer de les dones. Barcelona. La Neotipia. 61 pàg. Biblio teca de Tradicions Populars, 39.

1938 Refranys geogràfics. Barcelona. Imp. Comas. 45 pàg.

1951 Refranyer català comentat. Barcelona. Selecta. 274 pàg. + 1 làm. Biblloteca Selecta, 82 .

BAYERRI, Enric.

1936 Refranyer català de la comarca de Tortosa. Tortosa. Ed. "La Grafica". Vol. I, A-D. Lo Criteri Tortosi.

CALVO-SOTEL0, Joaquim.

1978 "Prólogo" en MARTINEZ KLEISER, L. Refranero General Ideológico Español, 29 ed. Madrid: Hernando.

CASARES, Julio.

1969 Introducción a la Lexicología Moderna. Madrid: Revista de Filo logía Española.

CASTILLO DE LUCAS, Antonio.

1940 Refranillero de la alimentación: divulgación de higiene a través de los refranes y dichos populares. Madrid: Graficas Reuni das.

1944 Refranes de aplicación médica. Madrid: Gráficas Reunidas,

1949 "Estudio prelíminar. Juan Sorapán de Rieros. Medicina Española contenida en proverbios vulgares de nuestra lengua". en: Biblioteca clásica de la Medicina Española. (Madrid), 16: 9-71.

1958 Folkmedicina. Madrid. Dossat.

1968 a "El ocio y la ociosidad; la fiesta y el festejo a través de los refranes españoles" Revista de Etnografía, XI: 327-362. $1968 \mathrm{~b}$ El folklore español. Madrid. Instituto Español de Antropología

CORREAS, Gonzalo.

1967 Vocabulario de refranes y frases proverbiales (1627). Bordeaux. Inst. d'Etudes Ibériques et Ibéro-Américanes.
FARNES, Sebastià.

1913 Assaig de Paremiologia catalana comparada. Barcelona. Ilustra ció Catalana, Vol. I.

1916 "Corpus paremiològic català" a: Arxiu d'Etnografia i Folklore de Catalunya, Questionari núm. 1. Barcelona.

GARCIA MORENO, Melchor.

1918 Catálogo paremiológico.

GELLA ITURRIAGA.

1944 Refranero del mar.

LIBRO-

1549 -de Apothegmas (que son dichos graciosos y notables de reyes y de philosophos insignes y de otros varones antiguos que y de philosophos insignes y de otros varones antiguos que
bien hablaron para nuestra doctrina y exemplo.....) Envers: Martín Nuncio.

LOPEZ DE MENDOZA, Iñigo (Marqués de Santillana).

1910 Refranes que dicen las viejas tras el fuego. Madrid: J.M. Sánchez. 16 hojas. (Reedición de la obra publicada en 1542 por Domenico Robertis en Sevilla).

LLULL, Ramon.

1746 Beati Raymundi Lulli. Liber de Mille Proverbis. Palmae Majori carum: Típ. Michael Cerdà \& Antich.

MARTINEZ KLEISER, Luis.

1953 Refranero general ideológico español. Madrid. Aguirre Torre, XXIX, 783 pàg.

NUÑEZ, Hernán.

1621 Refranes o proverbios en romance que coligió y glosó el Comendador. Lérida: Impr. Menescal. 4 hof. +399 fol.

PAREMIOLOGIA-

1915 -catalana sobre el Amor, la Fembra y lo Matrimoni. Barcelona. - catalana sobre el Amor, la Fembra y 10

RAMON ( Y VIDALES), Ramón.

1897 Cent refranys, estiragassats y comentats. Barcelona: Antoni López. 15 pag.

RODRIGUEZ MARIN, Francisco.

1926 Más de 21.000 refranes castellanos no contenidos en la copiosa colección del Maestro Gonzalo Correas. Madrid. Tip. de la Revista de Archivos, Bibliotecas y Museos.

193012.600 refranes más no contenidos en la colección del Maestro Gonzalo Correas ni en "Más de 21.000 refranes Castellanos" Madrid. Revista de Archivos, Bibliotecas y Museos.

1933 mejo. 16 pag. 
Arxiu d'Etnografia de Catalunya, $\mathrm{n}^{\circ} 1,1982,80-106$

ISSN: 0212-0372. EISSN: 2014-3885

http://antropologia.urv.cat/revistarxiu

1934 Los 6.666 refranes de mi última rebusca que con "más de 21.000 refranes" y "12.600 refranes" suman largamente 40.000 refranes castellanos son contenidos en la copiosa colección del Maestro Gonzalo Correas. Madrid. Bermejo. 198 pàg.

1941 Todavía 10.700 refranes más, no registrados por el maestro Correas ni en mis colecciones........... Madrid. Imp. "Prensa Española" 316 pàg.

ROSAL, Francisco del.

1560 Refranes. Madrid. Manuscrito de la Real Academia Española.

SANCHIS GUARNER, M.

1951 Calendari de Refranys. Barcelona. Barcino. 157 pàg. Biblioteca Folklorica Barcelona, Vol. I.

SBARBI, Josep $\mathrm{m}^{\mathrm{a}}$.

1875-76 El refranero General Español parte recopilado y parte compuesto por ........ Madrid. Imp. A. Gómez Fuentenebro. Vols. II, IV,
VII.

1891 Monografía sobre los refranes, adagios y proverbios castellanos y las obras o fragmentos que expresamente tratan de ellos en nuestra lengua. Madrid. Imprenta y Litografla de los Huérfanos. 412 pàg.

SORAPAN DE RIEROS, Juan (1616)

1975 La medicina española en proverbios. Madrid. Real Academia Na-

TORRES VILLARROEL.

1755 El Gran Piscator de Salamanca.

VALLES, Pedro.

1549 Libro de refranes, copilado por el orden del A, B, C. Zaragoza: J. Milian, Vda. de D. Hernán. 78 pags. 